\title{
Pflegetheorien in der Praxis - Was ist aus der historischen Vision im Praxisalltag geblieben?
}

\author{
Gerd Bekel
}

Online publiziert: 30 . November 2011

(C) Springer-Verlag 2011

Pflegetheorien finden in der Pflegepraxis keine oder nur begrenzte Anwendung. Es ist ruhig ,um die Theorieentwicklung in der Pflege geworden", beschreiben Mores und Schaeffer [3] ihr Fazit zum Sachstand der Anwendung von Pflegetheorien. Sie sehen die Ursache im Wesentlichen in den Passungsproblemen der sogenannten ,großen Entwürfe" begründet, die

a. auf Grund ihrer abstrakten Konstruktion den Anspruch haben, alle Situationen der Praxis zu beschreiben, dieses jedoch nicht einlösen können,

b. ihren Ausgangspunkt nicht bei den Problemen der Patienten haben, sondern bei den Pflegenden und

c. im Wesentlichen die Erfahrungen der TheoretikerInnen darstellen.

Eine weitere Ursache ist vermutlich in den unterschiedlichen Konstrukten der jeweiligen Pflegetheorien zu finden.

Die Notwendigkeit und Möglichkeit der Theorienutzung in der Pflegepraxis kann am Beispiel der menschlichen Selbstsorge diskutiert werden. Es gilt, Konzepte aus soziologischer, philosophischer, psychologischer und humanontogenetischer Perspektive zu betrachten und Hinweise zur Nutzung theoretischer Erkenntnisse für die Pflegepraxis abzuleiten.
Pflegepraxis benötigt eine pflegetheoretische Ordnung ihres Bildes vom Menschen zur Abgrenzung zu anderen Disziplinen und zur Erklärung pflegespezifischer Phänomene. Insbesondere die Anwendung der Pflegediagnostik in der Praxis benötigt eine konsequente Theorienutzung, die sowohl normative als auch phänomenologische Elemente beinhalten sollte.

\section{Literatur}

1. Bekel, G. Selbstsorge als zentraler Gegenstand des Pflegediskurses. In: Wessel KF, Scupin O, Bekel G, Diesner Th, Selbstsorge - Wissenschaftstheoretische. und gesundheitspolitische Dimensionen. Bielefeld: Kleine Verlag; 2007.

2. Wessel KF, Scupin O, Bekel G, Diesner, Th. Die Ordnung der Pflegewelt. Bielefeld:Kleine Verlag; 2009.

3. Moers M, Schaeffer D. Pflegetheorien heute: Wie können Sie die Praxisentwicklung fördern? Die Schwester/Der Pfleger.2006; 45. Jahrg., 2050-2053.
G. Bekel $(\bowtie)$

Institut für Pflegediagnostik \& Praxisforschung GbR,

Cloppenburg, Deutschland 